Revue d'histoire de l'enfance « irrégulière »

Le Temps de l'histoire

$20 \mid 2018$

Sexualités juvéniles

Les liaisons interdites. Histoire de l'inceste au XIX siècle

Jean-Jacques Yvorel

(2) OpenEdition

Journals

Édition électronique

URL : http://journals.openedition.org/rhei/4553

DOI : $10.4000 /$ rhei. 4553

ISSN : $1777-540 \mathrm{X}$

Éditeur

Presses universitaires de Rennes

Édition imprimée

Date de publication : 15 novembre 2018

Pagination : 221-223

ISBN : 978-2-7535-7571-4

ISSN : $1287-2431$

Référence électronique

Jean-Jacques Yvorel, «Les liaisons interdites. Histoire de l'inceste au xix siècle », Revue d'histoire de l'enfance « irrégulière » [En ligne], 20 | 2018, mis en ligne le 15 novembre 2018, consulté le 21 décembre 2020. URL : http://journals.openedition.org/rhei/4553; DOI : https://doi.org/10.4000/rhei.4553

(C) PUR 


\section{Comptes rendus d'ouvrages}

\section{Les liaisons interdites. Histoire de l'inceste au XIX siècle Fabienne Giuliani}

2014

Publications de la Sorbonne, Paris, 477 p., ISBN : 978-2-85944-776-2

Après, par exemple, l'infanticide étudié par Annick Tillier ${ }^{1}$ ou le parricide analysé par Sylvie Lapalus², Fabienne Giuliani nous propose avec cette Histoire de l'inceste au XIX siècle une nouvelle étude centrée sur un crime précis.

La prohibition de l'inceste est généralement présentée comme universelle et ce crime comme un invariant. Usant d'un oxymore, Fabienne Giuliani se propose d'inscrire dans la diachronie cet « invariant qui Varie " (p. 13).

La première partie, intitulée L'écriture de l'inceste, qui s'appuie essentiellement sur l'étude de l'évolution de la législation complétée par celle des représentations littéraires, médicales ou artistiques, démontre parfaitement que l'inceste est bien un objet historique dont le périmètre est redéfini en permanence. Organisée en trois chapitres chronologiques, elle commence logiquement par l'analyse du Code pénal de 1791 [Les fondements du crime. (1791-1832)] qui décriminalise l'inceste entre adultes, principe sur lequel le Code de 1810 ne reviendra pas. Cependant, en 1792 comme en 1804, le droit civil qui « sanctuarise la famille » (p. 49), maintient un certain nombre d'empêchements de parenté en matière de mariage. Le second chapitre [Variation sur l'interdit (1832-1875)] est articulé autour des grandes réformes pénales de 1832 et de 1863 . Si globalement ces réformes atténuent les peines, elles les aggravent en matière d'infractions à caractère sexuel et notamment d'inceste. La jurisprudence, qui classe les beaux-pères et les concubins dans la catégorie des parents incestueux renforce cette tendance législative. De leur côté, les médecins dénoncent de plus en plus vigoureusement les dangers de la consanguinité. Les élites ne manquent pas de stigmatiser les milieux populaires et l'inceste " ouvrier " suggéré à mots couverts par Villermé est affirmé par Jules Simon ou par Paul Bernard, procureur général d'Amiens et récipiendaire du prix Monthyon pour son livre sur L'histoire de l'autorité
1. Tillier Annick, Des criminelles au village. Femmes infanticides en Bretagne (1825-1865), Rennes, Presses universitaires de Rennes, 2001, $447 \mathrm{p}$.

2. Lapalus Sylvie, La mort du vieux. Une histoire du parricide au xixe siècle, Paris, Tallandier, 2004, 633 p. 
3. DaRYa Vassigh Denis,

«Les experts judiciaires face à la parole de l'enfant maltraité. Le cas des médecins légistes de la fin du xIx siècle ", Revue d'histoire de l'enfance «irrégulière ", $n^{\circ} 2,1999$, p. 97-111. paternelle en France (p. 11-112). L'enfant est la principale figure protagoniste de l'inceste. C'est donc logiquement que Fabienne Giuliani termine son exploration des textes législatifs avec les grandes lois de protection de l'enfance du 24 juillet 1889 et du 21 avril 1898. Elle montre notamment comment à travers la rhétorique de l'enfant martyr, "la violence physique continue d'oblitérer la violence sexuelle» (p. 165). Pour l'auteure, les Convergences (chapitre III) de la fin du siècle débouchent sur la constitution de l'inceste comme tabou tel que l'a défini Michel Foucault : «Affirmer que ça n'est pas permis, empêcher que ça soit dit, nier que cela existe" (p. 169).

La seconde partie, L'oeil de la justice, suit le travail de la justice de la saisine à la condamnation. L'inceste n'est pas une qualification juridique, il faut donc décrypter (chapitre IV), le débusquer dans les archives derrière d'autres incriminations, essentiellement des incriminations sexuelles comme l'attentat à la pudeur sans violence ou avec violences, la tentative de viol ou le viol. Mais il se cache aussi derrière les coups et blessures, voire les homicides. Nous avons là une belle déconstruction des catégories judiciaires : des faits très proches reçoivent des qualifications différentes et un même article du Code pénal peut être utilisé pour qualifier des faits très différents. L'intégration, parmi les sept départements retenus dans l'échantillon, des Alpes-Maritimes qui, avant son rattachement à la France dépendait de la législation sarde laquelle mentionnait explicitement l'inceste, permet un contrepoint. La question de la qualification posée, l'auteur observe la façon dont la justice est alertée. La plainte de la famille, - de la mère le plus souvent -, celle de la victime, ou plus rarement celle des proches, la rumeur villageoise, la lettre anonyme sont autant de voies pour parvenir à la saisine judiciaire. La justice informée, il lui faut fournir Les preuves de l'inceste (chapitre V). C'est notamment affaire des experts, essentiellement des médecins, qui sont bien souvent impuissants à prouver un passage à l'acte qui peut être très ancien ou qui, sauf usage de la force, laisse peu de traces. La suspicion grandissante qu'ils portent à la fin du siècle sur la parole de l'enfant, déjà soulignée par Denis Darya Vassigh ${ }^{3}$, contribue à renforcer leurs incertitudes. Les magistrats s'efforcent alors d'obtenir d'autres preuves qualifiées de "tangibles". Ces preuves circonstancielles "sont constituées de trois ensembles distincts : Les renseignements moraux sur l'inculpé et sa famille, les plans des lieux du crime et le courrier de la famille» (p. 232). En définitive, écrit Fabienne Giuliani, « une instruction pour inceste repose davantage sur des 
renseignements que sur des preuves" (p. 253). Labsence de réponse apportée par l'expertise et l'absence de preuves autres que circonstancielles font, du ballet des témoins (chapitre VI), un pilier de l'instruction. Les juges interrogent les voisins, la famille et bien sûr l'inculpé et sa victime. La confrontation entre l'auteur et la victime vient souvent clore le processus d'émergence de la vérité judiciaire. Les faits établis, reste à Punir (chapitre VII), du moins si l'instruction ne se termine pas par un non-lieu. Le taux d'acquittement $(11,3 \%)$ « est beaucoup plus faible que celui enregistré pour l'ensemble des crimes contre les personnes au niveau national » (p. 313) et les peines, majoritairement les travaux forcés, dans la fourchette haute des sanctions pour atteinte aux mœurs. Le huis clos est systématiquement requis dans ces affaires, aussi n'avons-nous aucune trace des débats devant les cours d'assises. Il ressort de cette seconde partie que la justice a une grande difficulté «à entrer dans le domaine privé et à s'intégrer dans les affaires familiales » (p. 330).

Dans la troisième et dernière partie, La maison du crime, Fabienne Giuliani tente d'éclairer les pratiques de l'inceste. L'inceste est-il Un crime ordinaire? (chapitre VIII). Elle commence par faire une Cartographie de l'inceste. Si les hommes sont majoritaires, les femmes ne sont pas absentes, et si l'inceste père/ fille est le plus répandu on trouve d'autres cas de figures (père/fils, mère/enfants des deux sexes). L'inceste est sans doute le crime le moins sociologiquement déterminé même si le fonctionnement du système judiciaire du XIX ${ }^{e}$ siècle en fait un «crime de pauvres » et il touche les villes comme les campagnes. L'auteure décrit ensuite les réactions des voisins (le silence le plus souvent) avant de se livrer à une réflexion sur le tabou de l'inceste. Fabienne Giuliani, nous fait ensuite pénétrer au sein du foyer incestueux (chapitre IX) et décrit les initiations, l'accoutumance, les violences. Enfin, parce que «l'inceste n'est pas qu'un crime, il est aussi une sexualité » (p. 399), l'auteure consacre son dernier chapitre aux amours incestueuses. Là il n'y a ni coup, ni violence, ni contrainte mais des amours impossibles, adelphiques par exemple. Il n'y a là, depuis 1791, pas de crime mais un interdit.

Ce livre, qui se situe à la jonction de multiples champs historiographiques (histoire de la justice, de la déviance, de la sexualité, de la famille, de l'enfance), est une contribution essentielle à celle de l'enfance "irrégulière ». Une chose est sûre, Fabienne Guiliani nous a persuadés que l'inceste n'est pas anhistorique et que cet « invariant» a, pour le moins, de multiples visages.

Jean-Jacques Yvorel 